EXTENDED REPORT

\title{
Uveitis in young adults with juvenile idiopathic arthritis: a clinical evaluation of 123 patients
}

\author{
K Kotaniemi, M Arkela-Kautiainen, J Haapasaari, M Leirisalo-Repo
}

Ann Rheum Dis 2005;64:871-874. doi: 10.1136/ard.2004.026955

See end of article for authors' affiliations

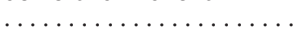

Correspondence to: Dr Kaisu Kotaniemi, Ophthalmology Department, Rheumatism Foundation Hospital, Pikijärventie 1, 18120 Heinola, Finland; kaisu. kotaniemi@phnet.fi

Accepted 18 October 2004
Objective: To examine the prevalence and characteristics of uveitis in young adults with juvenile idiopathic arthritis (JIA).

Methods: The study population consisted of 123 JIA patients born between 1976 and 1980 whose arthritis had been diagnosed and treatment first started at the Rheumatism Foundation Hospital in 1976 to 1995. A clinical re-evaluation was carried out by an ophthalmologist and a paediatric rheumatologist 16 years later on average.

Results: The mean age of the patients was 23.5 years, $72 \%$ were women, and $63 \%$ had oligoarthritis. During the course of the disease, diagnosis of uveitis had been made in 25 patients (20\%). Arthritis in the 19 patients with asymptomatic uveitis was more often ongoing than in the 98 patients without uveitis $(p=0.032)$. Asymptomatic uveitis was persistent in eight of the 19 cases $(42 \%)$, and arthritis was active in seven of these. Four of the six patients with attacks of symptomatic uveitis had parallel treatment for arthritis. In three of 19 patients with asymptomatic uveitis and in five of six with acute uveitis the eye inflammation had started after the age of 16. At the onset of arthritis the patients with asymptomatic uveitis were younger than those without uveitis $(p=0.002)$. Complications of uveitis developed in six patients but their sight remained good.

Conclusions: Asymptomatic uveitis continued into adulthood in almost half the uveitis patients. Most also had ongoing arthritis. Acute uveitis was often associated with persistent arthritis.
A symptomatic uveitis is an important manifestation of juvenile idiopathic arthritis (JIA). It occurs in about $20 \%$ of patients with oligoarthritis and less often (5$10 \%$ ) in those with rheumatoid factor (RF) negative polyarthritis. It is rare in systemic disease and uncommon in RF positive polyarthritis. ${ }^{1-4}$ In some patients, uveitis is acute, with redness and pain and typically affects boys aged 10 to 13 years, who often carry the HLA B27 antigen and may later develop spondyloarthropathy. The outcome of JIA has interested many researchers during the past three decades. ${ }^{5-9}$ However, only limited information is available on the prognosis of uveitis in JIA patients reaching adulthood. In a recent Danish 25 year retrospective study, uveitis had occurred in 10 of 65 adult patients with juvenile arthritis; the eye inflammation was persistent or chronic in three of these. ${ }^{10}$ The association between the activity of the uveitis and the activity of the arthritis remains unclear, although there is some evidence that uveitis may be associated particularly with severe arthritis. ${ }^{11}$ The aim of our study was to assess how often eye inflammation continues into adult life and whether the presence of uveitis is associated with ongoing arthritis.

\section{METHODS}

There are three main classification criteria of juvenile arthritis. $^{12}{ }^{13}$ (table 1)

The study was conducted at the Rheumatism Foundation Hospital, Heinola, Finland, where almost two thirds of all Finnish rheumatic children are treated at some phase of their disease. For JIA patients, the hospital is partly a tertiary referral centre that serves the whole country, but also a secondary care unit for those living nearby. The study population consisted of all the patients born between 1976 and 1980 in whom a diagnosis of juvenile arthritis was first made at the Rheumatism Foundation Hospital between 1976 and 1995. The files of the juvenile patients treated at the hospital were screened for arthritis. Those with juvenile arthritis meeting the criteria for juvenile idiopathic arthritis $(\mathrm{JIA})^{13}$ were included in the study.

In all, 187 eligible patients were found in the hospital patient records. Two of these had died and an additional four patients were excluded because of trisomy 21 . The rest (181 patients) were invited to a clinical examination at the Rheumatism Foundation Hospital; 123 of these (68\%) were able to take part in the study. The patient records of all 123 patients were examined at the Rheumatism Foundation Hospital and the information was completed from the records held in the relevant district hospitals. We analysed the group of non-participants for age at the onset, sex, type of arthritis at onset and age at the time of the re-evaluation. This group did not differ markedly from the study population, though the proportion of boys was greater among the nonparticipants ( $43 \%$ v 28\%).

An ophthalmologist and a paediatric rheumatologist evaluated all the patients. Erythrocyte sedimentation rate (ESR), C reactive protein, the level of rheumatoid factor, and HLA B27 status (if not determined before) were determined. A paediatric rheumatologist carried out a clinical examination and recorded the tender and swollen joint count. In this study, clinical remission of arthritis was assessed according to the criteria presented in table 2 .

The ophthalmic examination included the best corrected visual acuity, careful biomicroscopy and examination of the posterior part of the eye by Volk lens, applanation tonometry, Schirmer's test (positive value $<10 \mathrm{~mm} / 5 \mathrm{~min}$ with local anaesthesia), and an interview recording the presence of dry eyes. The previous ophthalmic history of the patients was evaluated as thoroughly as possible using the patient records of the Rheumatism Foundation Hospital as well as those from the central hospitals in Finland. Uveitis was regarded as

Abbreviations: JIA, juvenile idiopathic arthritis; RF, rheumatoid factor 
Table 1 The three main sets of criteria for childhood chronic arthritis

\begin{tabular}{|c|c|c|c|}
\hline & EULAR & ARA & ILAR \\
\hline $\begin{array}{l}\text { Name for the disease group } \\
\text { JAS, JPsA, IBD }\end{array}$ & $\begin{array}{l}\text { Juvenile chronic arthritis } \\
\text { (JCA) } \\
\text { Included (separately } \\
\text { listed) }\end{array}$ & $\begin{array}{l}\text { Juvenile rheumatoid } \\
\text { arthritis (JRA) } \\
\text { Excluded }\end{array}$ & $\begin{array}{l}\text { Juvenile idiopathic } \\
\text { arthritis (JIA) } \\
\text { Included }\end{array}$ \\
\hline $\begin{array}{l}\text { Duration of joint symptoms necessary } \\
\text { for the diagnosis of arthritis } \\
\text { Age of the patient at disease onset } \\
\text { Exclusion of other diseases } \\
\text { Definition of subtypes at } 6 \text { months' } \\
\text { disease duration }\end{array}$ & $\begin{array}{l}3 \text { months } \\
0 \text { to } 15 \text { years } \\
\text { Yes } \\
\text { Yes }\end{array}$ & $\begin{array}{l}6 \text { weeks } \\
0 \text { to } 15 \text { years } \\
\text { Yes } \\
\text { Yes }\end{array}$ & $\begin{array}{l}6 \text { weeks } \\
0 \text { to } 15 \text { years } \\
\text { Yes } \\
\text { Yes }\end{array}$ \\
\hline
\end{tabular}

ARA, American Rheumatism Association; EULAR, European League Against Rheumatism; IBD, arthropathy associated with inflammatory bowel disease; ILAR, International League Against Rheumatism; JAS, juvenile ankylosing spondylitis; JPsA, juvenile psoriatic arthropathy.

active if three or more cells were found in the anterior chamber or if the patient was receiving topical corticosteroids for uveitis, or both. Asymptomatic uveitis was mostly chronic anterior uveitis that had lasted for months or even years with minimal or no symptoms. It could only be detected by careful biomicroscopy. Acute anterior uveitis was defined as uveitis with redness, photophobia, and pain which usually healed in four to six weeks with topical treatment.

\section{Statistics}

Results are expressed as mean or median, with standard deviations or interquartile ranges (IQR). Statistical comparison between the groups was made by using the $t$ test, the Mann-Whitney test with exact $\mathrm{p}$ values, or the $\chi^{2}$ test. Kaplan-Meier curves were used to illustrate the findings of the cumulative proportions of uveitis. The most important descriptive values were expressed with 95\% confidence intervals (95\% CI). The $\alpha$ level was set at 0.05 in all the tests.

\section{RESULTS}

The main demographic and clinical characteristics of the study population are presented in table 3 . Uveitis had been detected in $25(20 \%)$ of the 123 patients.

Altogether 19 patients were affected by asymptomatic anterior uveitis with minimal or no ocular symptoms. At the onset of arthritis their mean age was 4.3 years (range 1.5 to 16.8) and at the time of diagnosis of asymptomatic uveitis their mean age was 10 years (range 2.6 to 23.5). The mean interval from the diagnosis of JIA to the diagnosis of uveitis was 4.8 years (range 0 to 20.2). Antinuclear antibody (ANA) positivity was found in seven of 19 patients (37\%). Only three patients had had one short episode of asymptomatic uveitis (duration less than three months). Five of the remaining 16 patients with chronic asymptomatic uveitis (duration more than three months) had eye inflammation in both eyes and in 11 cases this was unilateral. At the time of the clinical evaluation uveitis was still active in eight cases (mean

Table 2 Remission criteria of arthritis in juvenile idiopathic arthritis*

\begin{tabular}{lr}
\hline Criteria \\
\hline Morning stiffness (min) & $<15$ \\
ESR (mm/ $h$ ) & 0 \\
Swollen and tender joints ( $\mathrm{n}$ ) & 2 \\
Time without DMARDs or systemic prednisone before re- & \\
evaluation (years) & \\
\hline *All the criteria should be present for the diagnosis of remission. \\
†Additionally, no non-steroidal anti-inflammatory drugs or corticosteroid \\
injections were given during the previous two years. \\
DMARD, disease modifying antirheumatic drug; ESR, erythrocyte \\
sedimentation rate.
\end{tabular}

duration of uveitis 15 years) and arthritis was ongoing in all but one of them. Uveitis was detected in three of the 19 cases after the age of 16 .

At the onset of JIA the patients with asymptomatic uveitis were significantly younger than those without uveitis $(p=0.002$, table 3$)$. The mean interval from the diagnosis of arthritis to the evaluation study was 19.3 years (range 13 to 23 ) in patients with asymptomatic uveitis and 15.5 years (range 6 to 23$)$ in non-uveitis patients $(p=0.01)$ (table 3$)$. Among the asymptomatic uveitis group, oligoarthritis had progressed to extended oligoarthritis in five patients; all of whom had active arthritis and four had both active uveitis and ongoing arthritis at the time of re-evaluation. Arthritis was significantly more often active at clinical evaluation in patients with asymptomatic uveitis than in those without uveitis: in 16 of 19 cases ( $84 \%$; $95 \%$ CI, $60 \%$ to $97 \%$ )) $v 57$ of $98(58 \%(48 \%$ to $68 \%)) ; \mathrm{p}=0.032$. The risk ratio (RR) for active arthritis was 1.45 (95\% CI, 1.12 to 1.87 ) and the HLA B27 adjusted RR was 1.42 ( 1.10 to 1.83 ). For all the 25 uveitis patients, the RR for active arthritis was 1.38 (1.06 to 1.78); the HLA B27 adjusted RR was 1.31 ( 1.01 to 1.70 ), and active arthritis was found in 20 of 25 (80\% (59\% to 93\%)) uveitis patients $v 57$ of $98(58 \%(48 \%$ to $68 \%))$ non-uveitis patients $(\mathrm{p}=0.044)$. The median number of swollen and tender joints was 1 and 2, respectively, and median ESR was $7 \mathrm{~mm} / \mathrm{h}$ in 25 patients with uveitis compared with respective figures of 0,0 , and $11 \mathrm{~mm} / \mathrm{h}$ in non-uveitis patients $(\mathrm{p}=0.22,0.01$, and 0.023 , respectively).

Uveitis was acute anterior symptomatic (pain, photophobia, redness) in six cases, all of whom were HLA B27 positive and antinuclear antibody (ANA) negative. The mean age at the diagnosis of acute uveitis was 20 years (range 14.5 to 22), and in five cases uveitis appeared after the age of 16. The mean interval from the diagnosis of JIA to the diagnosis of uveitis was 9.1 years (range 1.9 to 18). Drug treatment for arthritis was being used in four of these patients, and two were in clinical remission without any treatment. The cumulative uveitis rate is shown in fig 1.

Complications of uveitis were seen only among the 19 patients with asymptomatic chronic uveitis. Secondary glaucoma was found in four cases (one had received a Molteno filtering device) and complicating cataract in five (four had had surgery, with intraocular lens implantation in three eyes). The visual status was good: unilateral visual acuity fell to $<0.1$ in only three patients, and all uveitis patients had normal (at least 0.8 ) binocular visual acuity. Forty per cent of patients with uveitis and $26 \%$ of the nonuveitis patients had dry eye symptoms and a Schirmer's test value of $<10 \mathrm{~mm} / 5 \mathrm{~min}$ at least in one eye (after topical anaesthesia) $(\mathrm{p}=0.15)$.

The drug treatment strategy of JIA patients is shown in table 4 . In addition, patients with uveitis were more often on 
Table 3 Demographic and clinical characteristics of young adults with juvenile idiopathic arthritis with or without asymptomatic or acute uveitis

\begin{tabular}{|c|c|c|c|c|}
\hline Variable & $\begin{array}{l}\text { History of } \\
\text { asymptomatic } \\
\text { uveitis }\end{array}$ & $\begin{array}{l}\text { No history of } \\
\text { asymptomatic } \\
\text { uveitis }\end{array}$ & $\mathrm{p}$ Value & $\begin{array}{l}\text { History of acute } \\
\text { uveitis* }\end{array}$ \\
\hline Number of patients & 19 & 98 & & 6 \\
\hline Female (n (\%)) & $16(84)$ & 71 (72) & 0.39 & $2(33)$ \\
\hline \multicolumn{5}{|l|}{ Age at onset of arthritis (years) (mean } \\
\hline $\begin{array}{l}\text { (SD)) } \\
\text { Diagnosis (course type) (n (\%)) }\end{array}$ & $4.3(3.4)$ & $7.7(4.4)$ & $\begin{array}{l}0.002 \\
0.33\end{array}$ & $10(4.1)$ \\
\hline Oligoarthritis & $10(53)$ & $63(64)$ & & $5(83)$ \\
\hline Extended oligoarthritis & $5(26)$ & $9(9)$ & & $1(17)$ \\
\hline Polyarthritis, RF negative & $2(11)$ & $21(21)$ & & $0(0)$ \\
\hline Polyarthritis, RF positive & $2(11)$ & $2(2)$ & & $0(0)$ \\
\hline $\begin{array}{l}\text { Psoriatic arthritis } \\
\text { Pas }\end{array}$ & $0(0)$ & $1(1)$ & & $0(0)$ \\
\hline Enthesitis related arthritis & $0(0)$ & $0(0)$ & & $0(0)$ \\
\hline Systemic onset arthritis & $0(0)$ & $2(2)$ & & $0(0)$ \\
\hline HLA B27 positive (n (\%)) & 7 (37) & $28(27)$ & 0.47 & $6(100)$ \\
\hline ANA positive (n (\%)) & 7 (37) & $20(20)$ & 0.14 & $0(0)$ \\
\hline \multirow{3}{*}{$\begin{array}{l}\text { Interval from diagnosis of arthritis to re- } \\
\text { evaluation (years) (mean (range)) } \\
\text { Age at re-evaluation (years) (mean } \\
\text { (range)) }\end{array}$} & 19.3 (13 to 23 ) & $15.5(6$ to 23$)$ & $<0.001$ & $15.3(9$ to 23$)$ \\
\hline & & & & \\
\hline & 23.7 (22 to 26 ) & 23.6 (21 to 26$)$ & 0.31 & 23.2 (22 to 25$)$ \\
\hline
\end{tabular}

cytotoxic drugs than those without uveitis: 11/25 $v$ 14/98 for all uveitis patients, and 9/19 $v$ 14/98 for those with asymptomatic uveitis $(\mathrm{p}<0.01$ for both)

\section{DISCUSSION}

Our aim in this study was to examine both the continuation of uveitis into adulthood and the association of active uveitis with ongoing arthritis in young adults with juvenile arthritis. We collected information of all juvenile patients treated at the Rheumatism Foundation Hospital between 1976 and 1995. We invited to the clinical re-evaluation all those in whom the diagnosis of arthritis had first been made at the hospital and who fulfilled the criteria for JIA. The importance of our study lies in the fact that the patients were invited to the re-evaluation at a mean of 16 years after their JIA had been diagnosed at the same hospital. The bias caused by the reduced number of patients attending $(68 \%)$ was probably acceptable because there were no major differences in the demographics and clinical features at the diagnosis of arthritis between patients attending and not attending for the clinical re-evaluation. The selection bias would have been more obvious if the focus had been on patients still being treated at the Rheumatism Foundation Hospital.

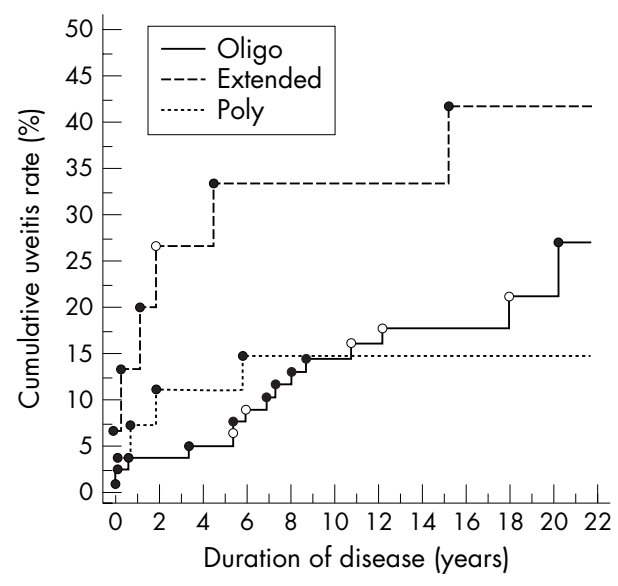

Figure 1 Cumulative rate of development of uveitis from the onset of arthritis in 123 patients with juvenile idiopathic arthritis: •, patients with insidious uveitis; $\circ$, patients with acute symptomatic uveitis.
At the re-evaluation, a thorough assessment of clinical status of arthritis and uveitis was made by an experienced team. We found that a remarkable proportion of patients with uveitis continued to have the condition into adult life and it was often associated with activity of the joint disease. Our study also showed very clearly that the patients with acute symptomatic uveitis had their first attack of uveitis later in life than those with asymptomatic uveitis. Moreover, they were all HLA B27 positive and ANA negative and four of them were boys. This is fully in accordance with our previous study. ${ }^{4}$ The overall frequency of HLA B27 in the Finnish population is as high as $14.5 \%$ and among JIA patients it is about $30 \% .^{5}$ Among patients with asymptomatic uveitis, arthritis began earlier and ANA positivity was more common than among those without uveitis. Also, positive HLA B27 was found more often in these patients. The relation between the activity of arthritis and the presence of uveitis in JIA has often been poorly documented. In some earlier studies, the activity of arthritis in patients with JIA associated uveitis tended to be greater than in those without, but the results did not reach statistical significance. ${ }^{14-16}$ Our previous prospective study of 372 recently diagnosed JIA patients with oligoarthritis or RF negative polyarthritis showed that uveitis was associated with active arthritis. ${ }^{11}$

According to the criteria for remission of JIA used in this study, the number of patients with some evidence of ongoing joint inflammation was greater in the group of patients with asymptomatic uveitis than in the non-uveitis group. Eight patients had active longstanding uveitis at the clinical evaluation and arthritis was in remission in only one of these. Also, the occurrence of dry eyes was slightly more common among uveitis patients, perhaps associated with the inflammatory activity in these patients.

The cumulative rate of the development of uveitis as described in fig 1 shows that it was mostly diagnosed shortly after the diagnosis of arthritis. In particular, those with extended oligoarthritis fell ill with uveitis quite early on. However, in some cases uveitis can begin after the age of 16, as was noted in three cases among the patients with asymptomatic uveitis, and even in five of the six cases with acute uveitis in this study. In particular, those with enthesitis related arthritis may develop recurrent acute uveitis in adulthood. While the first attack of uveitis in adulthood was usually acute and symptomatic, and was typically similar to the acute anterior uveitis occurring in HLA B27 positive 
Table 4 Drug treatment of 123 young adults with juvenile idiopathic arthritis at the time of the re-evaluation

\begin{tabular}{|c|c|c|c|}
\hline \multirow[b]{2}{*}{ Treatment } & \multirow[b]{2}{*}{$\begin{array}{l}\text { No history of } \\
\text { uveitis }(n=98)\end{array}$} & \multicolumn{2}{|c|}{ History of uveitis } \\
\hline & & $\begin{array}{l}\text { Asymptomatic } \\
(n=19)\end{array}$ & Acute $(n=6)$ \\
\hline \multicolumn{4}{|l|}{ Drugs: } \\
\hline Hydroxychloroquine & $14(14)$ & $0(0)$ & $0(0)$ \\
\hline Gold sodium thiomalate & $4(4)$ & $0(0)$ & $0(0)$ \\
\hline Azathioprine & $0(0)$ & $1(5)$ & $0(0)$ \\
\hline Sulfasalazine & $19(19)$ & $4(21)$ & $4(67)$ \\
\hline Methotrexate & 14 (14) & $6(32)$ & $2(33)$ \\
\hline Ciclosporin & $0(0)$ & $1(5)$ & $1(17)$ \\
\hline Leflunomide & $0(0)$ & $2(11)$ & $0(0)$ \\
\hline Prednisolone & $6(6)$ & $3(16)$ & $1(17)$ \\
\hline Etanercept & $0(0)$ & 1 (5) & $0(0)$ \\
\hline \multicolumn{4}{|l|}{ Strategy: } \\
\hline No drugs & $62(63)$ & $9(47)$ & $2(33)$ \\
\hline Single therapy & $21(21)$ & $4(21)$ & $2(33)$ \\
\hline Single therapy with prednisolone & $1(1)$ & $1(5)$ & $0(0)$ \\
\hline Prednisolone alone & $0(0)$ & $0(0)$ & $0(0)$ \\
\hline Combination therapy & $9(9)$ & $3(16)$ & $1(17)$ \\
\hline Combination therapy with prednisolone & $5(5)$ & $2(11)$ & $1(17)$ \\
\hline
\end{tabular}

diseases, the need of ophthalmic controls should be kept in mind when treating adult JIA patients.

Outcome studies of JIA mainly focus on the functional and social consequences of the disease..$^{6-9}$ There is one recent paper from the United Kingdom concerning the long term follow up of 246 adults with JIA where eye changes were also taken in account. ${ }^{17}$ Uveitis was found in $22 \%$ of the patients and it mostly occurred within the oligoarthritis or extended oligoarthritis groups. The most common complications of uveitis were cataract and glaucoma, which is in line with our study.

A recent Danish study focused specifically on the ocular complications and visual outcome in JIA. ${ }^{10}$ In this long term study 10 of 65 patients (15\%) had had uveitis; in three of them (33\%), uveitis was continuous at the follow up evaluation. However, the arthritis status was discussed only briefly. From the information given it could be calculated that their patients' arthritis was more often active in uveitis patients at the final phase of the study than in patients without uveitis $(50 \%$ v 35\%).

\section{Conclusions}

In over one third of JIA patients we found that asymptomatic uveitis continued into adulthood. The presence of uveitis was often associated with ongoing arthritis. Uveitis had led to some complications, but not to loss of visual acuity, perhaps thanks to new treatment methods for arthritis and uveitis. As some patients first developed asymptomatic uveitis in early adult life, routine eye examinations should be continued during this time.

\section{Authors' affiliations}

K Kotaniemi, M Arkela-Kautiainen, J Haapasaari, Rheumatism Foundation Hospital, Heinola, Finland

M Leirisalo-Repo, Helsinki University Central Hospital, Department of Medicine, Division of Rheumatology, Helsinki, Finland

\section{REFERENCES}

1 Kotaniemi K, Savolainen A, Karma A, Aho K. Recent advances in uveitis of juvenile idiopathic arthritis. Major review. Surv Ophthalmol 2003;48:489-502.

2 Rosenberg A. Uveitis associated with juvenile idiopathic arthritis: envisioning the future. J Rheumatol 2002;29:2253-4.

3 Zulian F, Martini G, Falcini F, Gerloni V, Zannin ME, Pinello L, et al. Early predictors of severe course of uveitis in oligoarticular juvenile idiopathic arthritis. J Rheumatol 2002;29:2446-53.

4 Kotaniemi K, Kautiainen H, Karma A, Aho K. Occurrence of uveitis in recently diagnosed juvenile chronic arthritis: a prospective study. Ophthalmology 2001;108:2071-5.

5 Savolainen HA, Lehtimaki M, Kautiainen H, Aho K, Anttila P. HLA B27: a prognostic factor in juvenile chronic arthritis. Clin Rheumatol 1998;17:121-4.

6 Oen K, Malleson PN, Cabral DA, Rosenberg AM, Petty RE, Reed M, et al. Early predictors of longterm outcome in patients with juvenile rheumatoid arthritis: subset-specific correlations. J Rheumatol 2003:30:585-93.

7 Fantini F, Gerloni V, Gattinara M, Cimaz R, Arnoldi C, Lupi E. Remission in juvenile chronic arthritis: a cohort study of 683 consecutive cases with a mean 10 year follow-up. J Rheumatol 2003;30:579-84.

8 Minden K, Niewerth M, Listing J, Biedermann T, Bollow M, Schontube M, et al. Long-term outcome in patients with juvenile idiopathic arthritis. Arthritis Rheum 2002; 46:2392-401

9 Foster H, Marshall N, Myers A, Dunkley P, Griffiths ID. Outcome in adults with juvenile idiopathic arthritis. A quality of life study. Arthritis Rheum 2003:48:767-75.

10 Zak M, Fledelius H, Pedersen FK. Ocular complications and visual outcome in juvenile chronic arthritis: a 25-year follow-up study. Acta Ophthalmol Scand 2003;81:211-15.

11 Kotaniemi K, Kotaniemi A, Savolainen A. Uveitis as a marker of active arthritis in 372 patients with juvenile idiopathic seronegative oligoarthritis or polyarthritis. Clin Exp Rheumatol 2002;20:109-12.

12 Brewer EJ, Bass J, Baum J, Cassidy JT, Fink C, Jacobs J, et al. Current proposed revision of JRA Criteria. JRA Criteria subcommittee of the Diagnostic and Therapeutic Criteria Committee of the America Rheumatism Section of The Arthritis Foundation. Arthritis Rheum 1977;20(suppl 2):195-9.

13 Petty RE, Southwood TR, Baum J, Bhettay E, Glass DN, Manners P, et al. Revision of the proposed classification criteria for juvenile idiopathic arthritis: Durban, 1997. J Rheumatol 1998;25:1991-4.

14 Cimaz RG, Fink CW. The articular prognosis of pauciarticular onset juvenile arthritis is not influenced by the presence of uveitis. J Rheumatol 1996;23:357-9.

15 Hertzberger-Ten Cate $R$, de Vries-Van Der Vlugt BCM, van SuijlekomSmit LWA. Cars A. Disease patterns in early onset pauciarticular juvenile chronic arthritis. Eur J Pediatr 1992;151:339-41.

16 Rosenberg AM, Oen KG. The relationship between ocular and articular disease activity in children with juvenile rheumatoid arthritis and associated uveitis. Arthritis Rheum 1986;29:797-800.

17 Packham JC, Hall M. Long-term follow-up of 246 adults with juvenile idiopathic arthritis: functional outcome. Rheumatology 2002;41:1428-35. 